\title{
Slab top dips resolved by teleseismic converted waves in the Hellenic subduction zone
}

\author{
A. Gesret, ${ }^{1,2}$ M. Laigle, ${ }^{2}$ J. Diaz, ${ }^{3}$ M. Sachpazi, ${ }^{4}$ M. Charalampakis, ${ }^{4}$ and A. Hirn ${ }^{2}$ \\ Received 21 July 2011; revised 19 September 2011; accepted 22 September 2011; published 22 October 2011.
}

[1] The variations of the arrival times and polarities with backazimuth and distance of teleseismic P-to-S converted waves at interfaces bounding the slab crust under the upper plate mantle are used to constrain the depth, dip angle and azimuth of the slab of the Hellenic subduction zone. A grid search is designed to estimate the model parameters. Dip values of $16-18^{\circ}$, with an azimuth of $20^{\circ}$ to $40^{\circ}$, are thus derived at 3 sites aligned over $50 \mathrm{~km}$ along the eastern coast of Peloponnesus. They are consistent with the variation from 54 to $61 \mathrm{~km}$ of the slab top depths constrained below each receiver. North of the Gulfs of Corinth and Evvia, a similar depth for the top of the slab is found at a distance from the subduction at least $100 \mathrm{~km}$ larger. This suggests flatter subduction of a different slab segment. Such a variation in slab attitude at depth across the region from south of the eastern Gulf of Corinth to north of Evvia is a candidate for the control of the recent or active localized crustal thinning of the upper plate we documented in earlier work, and of the surface deformation. Citation: Gesret, A., M. Laigle, J. Diaz, M. Sachpazi, M. Charalampakis, and A. Hirn (2011), Slab top dips resolved by teleseismic converted waves in the Hellenic subduction zone, Geophys. Res. Lett., 38, L20304, doi:10.1029/2011GL048996.

\section{Introduction}

[2] In the Hellenic subduction region (Figure 1), the geometry of the slab top has remained only loosely constrained by the spatial distribution of seismicity [e.g., Papazachos et al., 2000] or travel time tomography [e.g., Bijwaard et al., 1998], with a spread or resolution of tens of kilometers with respect to a dipping plane. The size of the seismic velocity anomaly shown by seismic tomography is huge for a slab, but because its internal structure is not resolved, it has been considered as resulting from a single subduction having been active throughout most of the Mesozoic and the entire Cenozoic [e.g., Jolivet and Brun, 2010]. However slab detachments and tears have been considered [e.g., Wortel and Spakman, 2000], among which the evidence for the one suggested to be associated to the Kefalonia fault has remained elusive.

\footnotetext{
${ }^{1}$ Centre de Géosciences, Mines ParisTech, Fontainebleau, France.

${ }^{2}$ Sismologie, Institut de Physique du Globe de Paris, UMR 7514, CNRS, Paris, France.

${ }^{3}$ Instituto Jaume Almera, Consejo Superior de Investigaciones Científicas, Barcelona, Spain.

${ }^{4}$ Institute of Geodynamics, National Observatory of Athens, Athens, Greece.

Copyright 2011 by the American Geophysical Union. 0094-8276/11/2011GL048996
}

[3] A better resolution may be reached with the receiverfunction (RF) method at an array of temporary seismometers, since the dipping slab may be sampled at the spacing of the receivers deployed. From teleseismic P-to-S converted waves at interfaces with sharp velocity contrasts, the slab top and Moho, can be identified and located. We have illustrated that such interfaces with less than $10 \mathrm{~km}$ separation in depth can be resolved, and we have constrained consistently over several receivers in Peloponnesus such a thin low-velocity layer (LVL) between the upper plate mantle and the slab mantle [Gesret et al., 2010]. This is the typical thickness of oceanic crust and hence for the first time we documented that the slab under Peloponnesus is unambiguously made of oceanic lithosphere.

[4] The dip angle and the dip azimuth of the slab top were not precisely known yet in this region though it has been approached early on by teleseismic converted waves studies [van der Meijde et al., 2003; Li et al., 2003]. The slab dip under Peloponnesus could not be resolved by the sparse receiver coverage of the broad scale study of Sodoudi et al. [2006]. From a profile of receivers aligned along the $\mathrm{N} 60^{\circ} \mathrm{E}$ azimuth through Peloponnesus to the Corinth Isthmus, Suckale et al. [2009] have derived a 15$20 \mathrm{~km}$ thick LVL with a constant dip of $22^{\circ}$ from about 30 to $90 \mathrm{~km}$ depth by an advanced method of 2D inversion of the primary converted waves and of the multiples, i.e., backscattered waves at the free surface [Rondenay et al., 2001]. Their preferred interpretation of this thick LVL, which is twice that of an oceanic crust, is that there is also serpentinization of an additional mantle domain above or below the slab crust. Since the position of the slab top inside this thick LVL is not precisely defined, neither is the value of the slab dip angle. Nor can the slab dip azimuth, that is the true dip direction.

[5] In the present study, we nevertheless will constrain the geometry of the slab under the receivers taking advantage of the clearly recorded signals we obtained. We resolve the slab top depth, dip value and dip azimuth by an analysis of the variation of converted wave times and polarities among earthquakes with different azimuths and distances. Such a resolution can be obtained only from processing high-quality data up to higher frequencies than in the usually considered broad band range. This is because the times of the successive negative and positive peaks from the top and base of the slab crust lose their relation to the depth of the interfaces for longer period signals, since in this domain of the thin-layer response, the spacing and amplitude of the peaks become a function of the period of the incoming P signal itself [Gesret et al., 2010].

[6] We use high-frequency and resolution $\mathrm{P}$ to $\mathrm{S}$ converted signals at those of the several tens of receivers in the swath from SE Peloponnesus through central Greece in Figure 1, which have recorded earthquakes with a good 


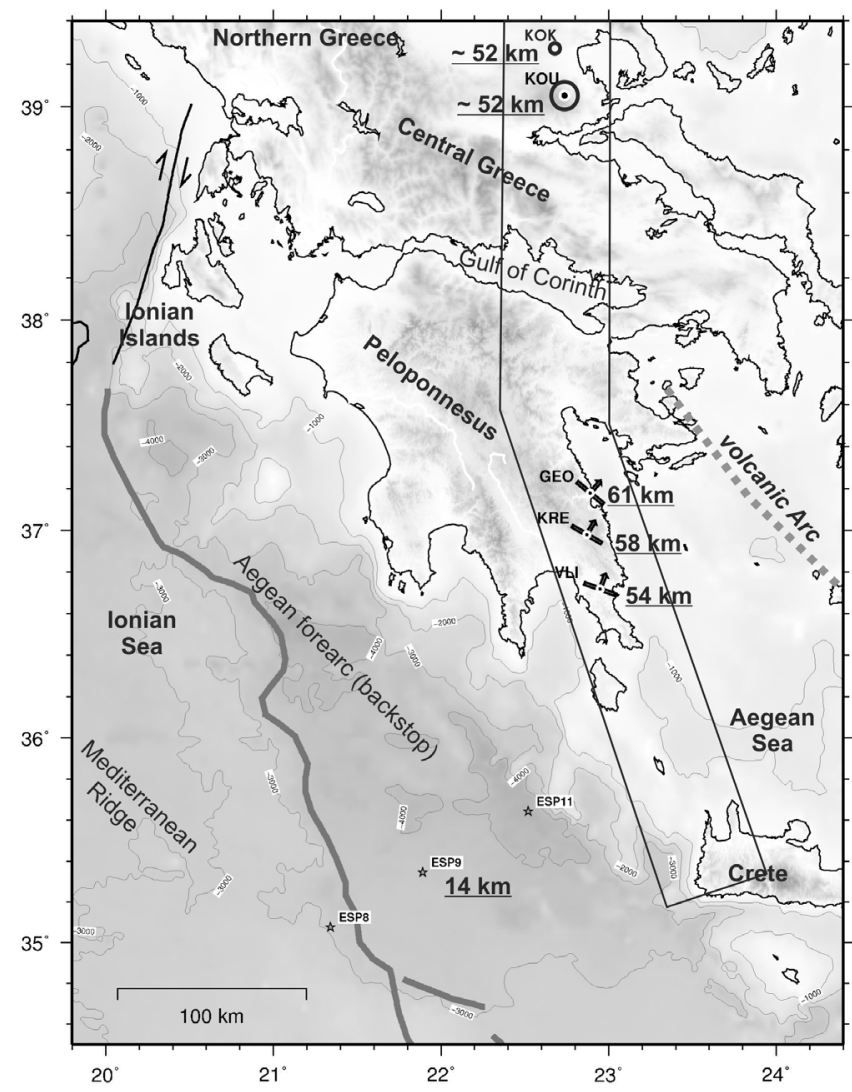

Figure 1. Location map of seismometer stations labelled VLI, KRE, GEO in the south and KOU, KOK in the North discussed in text, within swath indicated of temporary deployment of seismometers. At each of these station sites the slab top depth is indicated in kilometres and its direction of dip is indicated by an arrow, except at KOU in the North where the dip is too small to be resolved. The grey bold line offshore is the limit of the Aegean forearc, upper plate backstop, that is the plate boundary at sea-bottom. Its northward continuation as the active Cephalonia strike-slip fault is indicated.

azimuthal distribution, in order to place quantitative constraints on the depth, dip angle and dip azimuth of the slab top.

\section{Data and Processing}

[7] In the framework of the 'THALES WAS RIGHT' project, several tens of temporary seismometers have been deployed in a swath along Eastern Peloponnesus and northward across the Gulf of Corinth (Figure 1). A standard receiver-function, RF, processing has been applied to the 3-component seismograms of teleseismic body waves [e.g., Stammler, 1993; Kind et al., 1995; Galvé et al., 2002]. The vertical and the two horizontal components are first rotated into the local $\mathrm{P}, \mathrm{SV}, \mathrm{SH}$ ray-based coordinate system hereafter also called L-, Q-, and T-components. After deconvolution of the $\mathrm{Q}-$ and $\mathrm{T}$-components by the $\mathrm{P}$ signal on the L-component, we obtain the SV or Q-RF containing the SV converted from $\mathrm{P}$ on the normal to it in its vertical plane of incidence, and the SH or T-RF on the normal to this vertical plane of incidence, which is null except for dipping or anisotropic layers beneath the receiver. Since we aim at detecting dipping interfaces, we also consider the T-RF as they generate signal on this component. The $\mathrm{P}$ to $\mathrm{S}$ converted waves at the top and bottom of the LVL at the Hellenic slab top at station VLI (Figure 1) in this SE Peloponnesus study region, appear on the SV-RF as a trough followed by a peak at about $\sim 6-7 \mathrm{~s}$ after the $\mathrm{P}$ arrival. This is the signal from opposite polarity converters at about 60 and $70 \mathrm{~km}$ depth in a standard regional velocity model of a $30 \mathrm{~km}$ thick crust with $\mathrm{Vp}=6.5 \mathrm{~km} / \mathrm{s}$ on top of a normal velocity mantle. The robustness and success of the deconvolution can be illustrated (Figures S1a and S1b in the auxiliary material) for the M 9.3 Sumatra megathrust earthquake with its very complex and long source time and space function. ${ }^{1}$

[8] Some of the temporary seismometers have been deployed long enough to obtain an adequate coverage in terms of backazimuth and epicentral distance. The comparison of RF retrieved for earthquakes in very different azimuths show clear variations in terms of polarities and arrival times of the converted waves at the slab top. In the subsequent analysis, we use these variations to search for the depth, dip value and azimuth parameters of a dipping interface, as it is expected in this subduction zone context.

[9] With the advent of portable broadband seismometers, deployment of several of them along a line has been used to interpret topography of interfaces along vertical crosssections from RF teleseismic data by stacking and imaging techniques [e.g., Kosarev et al., 1999; Galvé et al., 2002]. In these approaches, converted wave amplitudes are first backpropagated along their ray path to their conversion points, then projected and stacked as a depth-section along the line of receivers.

[10] This imaging is justified only if the real structure is 1D-layered. Indeed if there is a dipping structure, the converted ray does not remain in the azimuth of the incoming $\mathrm{P}$ wave and the incidence is considered, according to Snell's law with respect to the normal of the dipping interface and not anymore with respect to the vertical axis. Hence the converted $\mathrm{S}$ azimuth, incidence angle and travel time are different from the case of a horizontal interface. Nevertheless the transmitted $\mathrm{P}$ does not undergo the same complexity in the case of the slab crust between upper plate mantle and slab mantle, since a LVL behaves like a thin inclusion between parallel boundaries in optics. The arrival time delay of the converted $\mathrm{S}$ with respect to the first arriving $\mathrm{P}$ corresponds to the sampling of the conversion interface at a point that is different from the case of a horizontal interface. For instance, for a LVL at $60 \mathrm{~km}$ depth, with a $20^{\circ}$ dip angle, the assumption of horizontal layering would induce errors in piercing point positions reaching $10 \mathrm{~km}$ in the updip direction (Figure S2a), and underestimation in depths reaching $2 \mathrm{~km}$, as well as underestimation of $1^{\circ}$ of the dip value.

[11] With respect to the isotropic horizontally layered case, the effects of a dipping converter is to generate signal also on the SH and not only SV RF, and to cause a variation of lag time with backazimuth, with both having specific patterns with respect to the dip direction and value. Significant $\mathrm{SH}$ amplitudes are indeed found, and their variation

${ }^{1}$ Auxiliary materials are available in the HTML. doi:10.1029/ 2011 GL048996. 
with backazimuth documented (Figure S6). Concerning the variation of lag time with azimuth, a range of only $0.5 \mathrm{~s}$ is expected for $15^{\circ}$ dip. However, as we illustrated from synthetics and observations [Gesret et al., 2010], there can be an effect on the picked times of the deformation of the waveforms by the resonance or thin layer effect that depend on signal spectrum with respect to LVL parameters. This is illustrated for two earthquakes from a same location and similar magnitudes for which the time lags picked for the top of the converting LVL differ by $0.3 \mathrm{~s}$ because of different signal spectra (Figure S1b), which is very significant with respect to resolving variations with azimuth of $0.5 \mathrm{~s}$ due to dip.

\section{Grid Search for Slab Depth, Dip Angle and Dip Direction}

[12] $\mathrm{P}$ to $\mathrm{S}$ converted waves at dipping interfaces are known to show also amplitude on the SH or T-RF, polarity reversals on the $\mathrm{Q} R \mathrm{RF}$ and/or T RF and variation of converted waves arrival times. These observations depend all on the backazimuth and incidence of the incoming $\mathrm{P}$ wave with respect to the dip direction and on the value of the incidence angle compared to the dip value. Opposite polarities for SH-RF are documented here between NNW and ESE backazimuths, indicating a SSW-NNE dip direction (Figure S6). Alternatively such two-lobed symmetry could be due to a horizontal converter with anisotropy in the overburden, but only in the special case of a strongly dipping axis of symmetry. A case has been reported for the Cascadia slab [e.g., Park et al., 2004] where the wave pattern indicated an axis of symmetry along the strike, whereas it would be along dip in the dipping converter model and absence of anisotropy. We will check that here a dipping converter is the cause of the wave pattern by using several receivers on a line instead of only a single station analysis. The dip value and azimuth derived at each receiver for itself in the hypothesis of a dipping converter should then be consistent with the different depths of the converter under each receiver along the line.

[13] We explore the constraints that can be placed on the geometry of the interface under a receiver, by a grid search among its depth and dip parameters for the fit of polarities and arrival times of synthetics with the observations. To illustrate our approach, we use the VLI station, in Eastern Peloponnesus (Figure 1) of the permanent network of the National Observatory of Athens. For this station that sampled the whole range of azimuths (Figure S2b), we selected 44 earthquakes for the SV-RF polarity and arrival time and the clearest 25 among them showing amplitude on the $\mathrm{SH}$ RF for its polarity. We compute the synthetic polarities and arrival times of the converted waves [Owens et al., 1988] at the slab top and the corresponding receiver functions [Ammon, 1991]. The same procedure applied to the negative peak of the top of the slab crust has also been applied to the positive peak of its Moho, with consistent results for the dip and a difference in depth of 7 to $10 \mathrm{~km}$. The following description and figures are for the case of the negative signal peak from the slab top.

[14] Polarities are not dependent on the depth of the conversion interface. Hence in a first step we explore the model parameter space for the dip angle value and dip direction azimuth which minimize the SV- and SH-RF polarity misfit between observations and synthetics. The SV-RF polarities (Figure 2a) allow us to constrain unambiguously the dip angle to lie between 0 and $20^{\circ}$. For the dip direction, a rather broad range from $\mathrm{N}$ to $\mathrm{N} 90^{\circ} \mathrm{E}$ azimuth, satisfies the 44 observed polarities The SH-RF polarities (Figure $2 \mathrm{~b}$ ) allow to reduce the range of dip values, constraining them to be above $12^{\circ}$, with a minimum misfit at $16^{\circ}$. For the dip azimuth, the value is then considerably reduced to a range between $\mathrm{N} 20^{\circ} \mathrm{E}$ and $\mathrm{N} 50^{\circ} \mathrm{E}$, with the minimum at $\mathrm{N} 35^{\circ} \mathrm{E}$. This azimuth of the minimum misfit indeed satisfies the 20 clearest among the 25 data. A dipping slab top model is thus comforted to account for the SH-RF.

[15] The arrival time observations on the SV-RF are then used (Figures $2 \mathrm{f}$ and $2 \mathrm{~g}$ ) in order to explore the depth versus the dip angle parameter in the range defined above, in a method inspired by Baker et al. [1996]. The absolute values of the residuals, observed-predicted time in the standard velocity-depth model mentioned (Figure 2f) and their algebraic values (Figure $2 \mathrm{~g}$ ) are then summed for each model. The intersection of the area of the minimum of the former by the zero line of the latter defines the depth for the slab top under the receiver as $54 \mathrm{~km}$ within a kilometer for the dip values from 0 to $18^{\circ}$, within which admissible values from polarities are contained.

[16] The arrival times for the slab top depth of $54 \mathrm{~km}$ can then also be used to further refine the dip angle value and dip direction azimuth values independently from the polarity misfit analysis that needs data from critical backazimuths. For these two model parameters, the mean of the absolute values of time residuals are contoured in Figure $2 \mathrm{c}$ and the mean of their algebraic values in Figure 2d. Finally, Figure 2e shows the intersection of acceptable domains from polarities (under the blue curve for radial and inside the magenta curve for transverse) and times (inside the green curve for the minimum of the mean of absolute values of time residuals and on the zero curve of the algebraic value of time residuals in stippled red). The intersection allows to restrict the dip angle value between $15^{\circ}$ and $18^{\circ}$ and the dip direction azimuth between $\mathrm{N} 20^{\circ} \mathrm{E}$ and $\mathrm{N} 30^{\circ} \mathrm{E}$. In the best fit model the slab top depth is sampled to range from 49 to $56 \mathrm{~km}$ over about $20 \mathrm{~km}$ along dip (Figure S3a), with a random distribution of residuals with azimuth and incidence angle (Figure S3b)

[17] In order to check the consistency of the slab dip angle and direction at the scale of several tens of kilometers, our approach has been applied to other sites as well. However, very clear RF are required to resolve time picking on highfrequency signals, and due to the low level of seismicity in certain azimuths, only few sites have acquired sufficient data. This is the case for two other stations KRE and GEO located 25 and $50 \mathrm{~km}$ NNE from VLI. Beneath KRE, the slab top is at $58 \mathrm{~km}$, its Moho at $65 \mathrm{~km}$, and is dipping by about $16^{\circ}$ in the $\mathrm{N} 30^{\circ} \mathrm{E}$ direction. Under GEO (Figure S4) the slab top is found to be at $61 \mathrm{~km}$, and the base of its crust at $70 \mathrm{~km}$, with a dip angle value of about $18^{\circ}$ in the $\mathrm{N} 40^{\circ} \mathrm{E}$ azimuth. The regional depth variation computed from a mean dip of $16^{\circ}$ in the $\mathrm{N} 30^{\circ} \mathrm{E}$ direction is consistent with the depths given by our grid search, to within a kilometer.

[18] In order to check the variation of the slab top at the scale of a hundred kilometers, we analyzed with the same approach the slab top beneath KOU located in central Greece to the North of the Corinth and Evvia gulfs (Figure 1). Minimization of the residuals gives a slab top depth of $52 \mathrm{~km}$ 

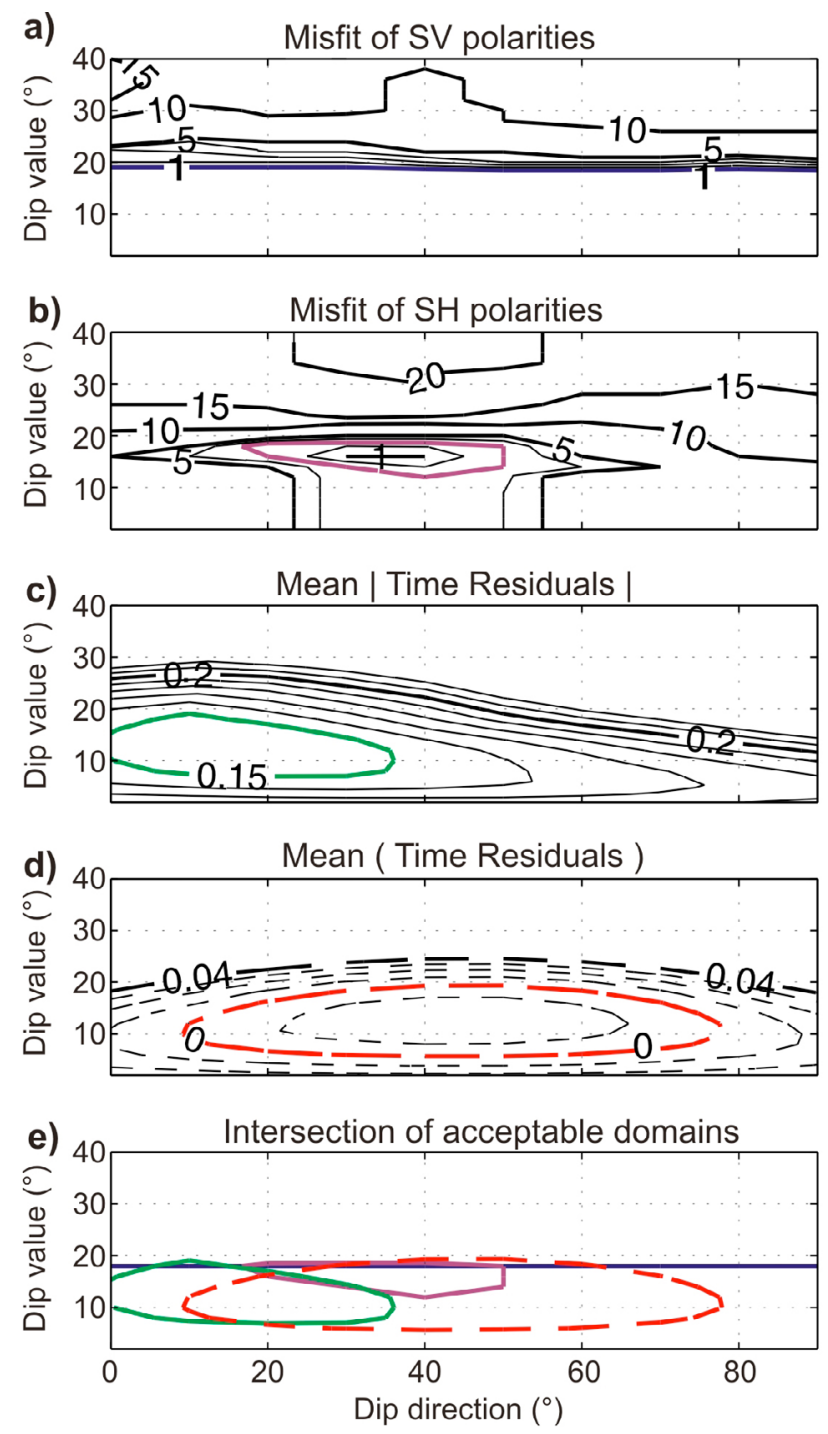

f)
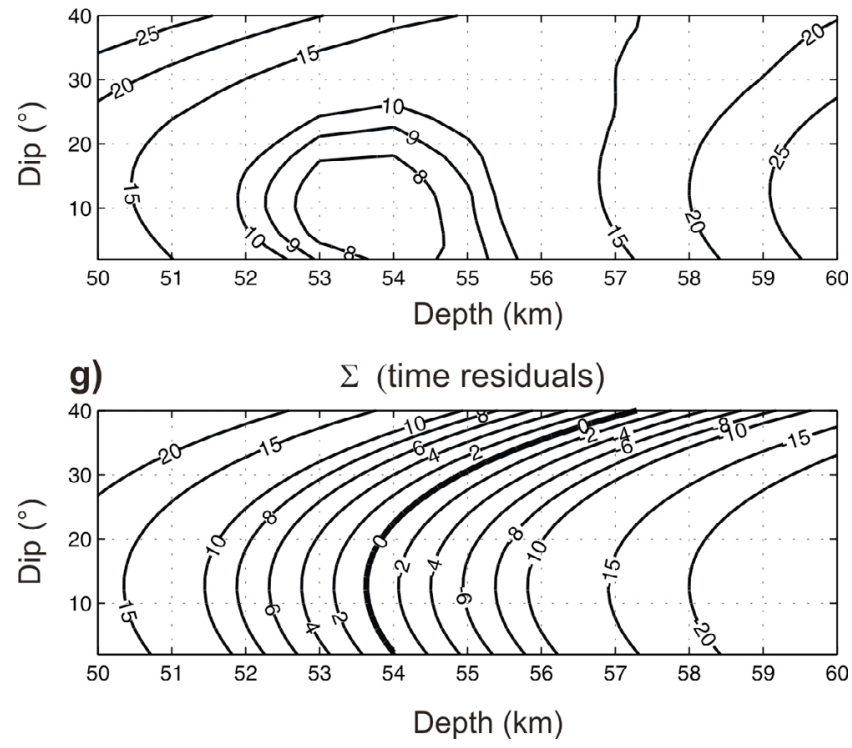

(Figure S5). This is about the same depth as for the three stations in SE Peloponnesus, whereas the station is located at a much larger distance from the subduction boundary at the outer limit of the forearc west of Cephalonia. Hence, to the north the average dip appears much smaller. This may explain that we could not resolve here locally from the $20 \mathrm{~km}$ aperture spanned by single station data neither a value for the dip angle significantly different from zero for the dip angle, nor an estimate of dip azimuth.

\section{Conclusions and Discussion}

[19] From the analysis of the variation with azimuth and angle of incidence of the arrival times of P-to-S converted waves and their polarities we constrain under SE Peloponnesus a slab dipping with an angle of $16-18^{\circ}$ in a direction of azimuth $\mathrm{N} 20^{\circ} \mathrm{E}$ to $\mathrm{N} 40^{\circ} \mathrm{E}$. This estimation of slab dip value and azimuth is consistent with the variation of the slab depth constrained simultaneously under each receiver. This increases northwards from 54 to $61 \mathrm{~km}$ under three receivers aligned over $50 \mathrm{~km}$ along the eastern coast of Peloponnesus (Figure 1).

[20] These dip directions of N 20-40 $\mathrm{E}$ appear to have more northerly azimuth values than the $\mathrm{N} 60^{\circ} \mathrm{E}$ azimuth perpendicular to the general strike of the subduction zone. North of the Gulfs of Corinth and Evvia, for instance at station KOU and KOK (Figures S1d and S1e), a similar depth of $52 \mathrm{~km}$ is found for a clear LVL which we interpret similarly as being the slab crust. The slab top thus documented is much shallower than the $160 \mathrm{~km}$ deep slab top inferred there by Sodoudi et al. [2006] mainly from S-to-P conversion. The shallow slab segment sampled at $52 \mathrm{~km}$ depth north of the Gulf of Corinth and Evvia by our observations is obviously not in continuity with the slab under Peloponnesus. The northward prolongation of that one, with its dip measured, and from its depth under Peloponnesus would lie much deeper. We note that the two observations would not be contradictory if the huge volume of the seismic tomography velocity anomaly, that is much thicker than

Figure 2. Station VLI. Grid search of model space for depth, dip angle value and dip direction azimuth of the slab top to minimize differences between model synthetics and observations of conversion times and polarities. Horizontal axis is dip direction azimuths from $\mathrm{N}$ to $\mathrm{N} 90^{\circ} \mathrm{E}$ and vertical axis is dip angle values from 0 to $40^{\circ}$. (a) Number of polarity misfits of 44 data of converted $\mathrm{S}$ on the SV, i.e., Q-RF. (b) Number of polarity misfits of 25 data of converted $\mathrm{S}$ on the SH, i.e., T-RF. (c and d) Mean of absolute values, respectively of algebraic values in seconds of time residuals, observed-synthetics, computed for a $54 \mathrm{~km}$ depth to the top of the slab derived from our analysis in Figure $2 \mathrm{e}$ and $2 \mathrm{f}$. (e) The preferred dip azimuth on horizontal axis and dip angle on vertical axis are defined by the intersection of curves enclosing minima of acceptable domains of Figure $2 \mathrm{a}$ in blue, Figure $2 \mathrm{~b}$ in magenta, Figure $2 \mathrm{c}$ in green, and their intersection by the dotted red curve of Figure 2c. ( $\mathrm{f}$ and $\mathrm{g}$ ) Horizontal axis is slab top depths from 50 to $60 \mathrm{~km}$ and vertical axis is dip angles value from 0 to $40^{\circ}$ for respectively minimizing the mean of absolute and zeroing the sum of algebraic values in seconds of residuals of observed-synthetic times. 
expected for a regular slab, would be made of superposed slab segments that seismic tomography cannot resolve.

[21] The depth of the slab top we define in the North is about the same as under receivers in SE Peloponnesus, but the distance of KOU and KOK from the subduction plate boundary is much larger, by at least $100 \mathrm{~km}$ along the normal to the forearc limit to up to $180 \mathrm{~km}$ when taken along the plate convergence vector. The average dip from under the backstop edge thus appears much smaller in this northern region. This may explain that a dip value and direction could not be resolved here locally from the $20 \mathrm{~km}$ aperture spanned by single station data (Figure S5) suggesting that it is underlain by a different segment of the slab. Also, the multiscale analysis of KOU and KOK did not succeed to constrain a layer as thin as an oceanic crust with respect to sites in Peloponnesus, since the negative to positive peak interval does not get that narrow even towards the higher frequencies (Figures S1d and S1e). A possibly larger thickness of the slab top LVL would be consistent with a continental or continental margin nature of the slab to the North. A corresponding larger buoyancy would also account for its shallower position and flatter dip, with respect to the domain south of the Gulf of Corinth where we have shown the oceanic nature of the slab by resolving its thin crust [Gesret et al., 2010].

[22] The seismic observations hence suggest a slab tear or major warping in-between the south of the Gulf of Corinth and the north of the Gulf of Evvia. Across this region comprising the eastern Gulf of Corinth, a broad region of complex thinning of the crust of the upper plate was revealed by the Moho map derived from artificial source and natural earthquake refraction-reflection seismics [Sachpazi et al., 2007]. This is also the region of surface deformation described as the Central Hellenic Shear Zone by Papanikolaou and Royden [2007]. The region of major variation of upper plate crustal thickness and the related region of surface deformation appear from the present study to be underlain by a domain of variation in attitude and possibly nature of slab segments, which may have exerted the primary control on the tectonic evolution through the plate above. From the recognition of such possibly sharp variations in slab depth early during the field experiment, receivers have been moved to achieve a denser and more $2 \mathrm{D}$ sampling over a broad swath, rather than remain along the initial line of receivers, in order to reveal the details of how the slab varies in-between (M. Sachpazi et al., manuscript in preparation, 2011).

[23] Acknowledgments. This research has been supported by the European Union FP6 NEST_INSIGHT programme, under project THALES WAS RIGHT.

[24] The Editor wishes to thank Laurent Jolivet and Frederik Tilmann for their assistance evaluating this paper.

\section{References}

Ammon, C. J. (1991), The isolation of receiver effects from teleseismic P waveforms, Bull. Seismol. Soc. Am., 81, 2504-2510.

Baker, J. E., J. B. Minster, G. Zandt, and H. Gurrola (1996), Constraints on crustal structure and complex Moho topography beneath Pinon flat, California, from teleseismic receiver-function, Bull. Seismol. Soc. Am., $86,1830-1844$.

Bijwaard, H., W. Spakman, and E. R. Engdahl (1998), Closing the gap between regional and global travel time tomography, J. Geophys. Res., 103, 30,055-30,078, doi:10.1029/98JB02467.
Galvé, A., M. Sapin, A. Hirn, J. Diaz, J.-C. Lépine, M. Laigle, J. Gallart, and M. Jiang (2002), Complex images of Moho and variation of Vp/Vs across the Himalaya and South Tibet, from a joint receiver-function and wide-angle-reflection approach, Geophys. Res. Lett., 29(24), 2182, doi:10.1029/2002GL015611.

Gesret, A., M. Laigle, J. Diaz, M. Sachpazi, and A. Hirn (2010), The oceanic nature of the African slab subducted under Peloponnesus: Thin-layer resolution from multiscale analysis of teleseismic P-to-S converted waves, Geophys. J. Int., 183, 833-849, doi:10.1111/j.1365-246X.2010.04738.x.

Jolivet, L., and J.-P. Brun (2010), Cenozoic geodynamic evolution of the Aegean, Int. J. Earth Sci., 99, 109-138, doi:10.1007/s00531-0080366-4.

Kind, R., G. L. Kosarev, and N. V. Petersen (1995), Receiver-functions at the stations of the German Regional Seismic network (GRSN), Geophys. J. Int., 121, 191-202, doi:10.1111/j.1365-246X.1995.tb03520.x.

Kosarev, G., R. Kind, S. V. Sobolev, X. Yuan, W. Hanka, and S. Oreshin (1999), Seismic evidence for a detached Indian lithospheric mantle beneath Tibet, Science, 283, 1306-1309, doi:10.1126/science.283. 5406.1306.

Li, X., G. Bock, A. Vafidis, R. Kind, H.-P. Harjes, W. Hanka, K. Wylegalla, M. Van Der Meijde, and X. Yuan (2003), Receiver function study of the Hellenic subduction zone: Imaging crustal thickness variations and the oceanic Moho of the descending African lithosphere, Geophys. J. Int. 155, 733-748, doi:10.1046/j.1365-246X.2003.02100.x.

Owens, T. J., R. S. Crosson, and M. A. Hendrickson (1988), Constraints on the subduction geometry beneath western Washington from broadband teleseismic waveform modeling, Bull. Seismol. Soc. Am., 78, 1319-1334.

Papanikolaou, D. J., and L. H. Royden (2007), Disruption of the Hellenic arc: Late Miocene extensional detachment faults and steep PlioceneQuaternary normal faults-Or what happened at Corinth?, Tectonics, 26, TC5003, doi:10.1029/2006TC002007.

Papazachos, B. C., V. G. Karakostas, C. B. Papazachos, and E. M. Scordilis (2000), The geometry of the Wadati-Benioff zone and lithospheric kinematics in the Hellenic arc, Tectonophysics, 319, 275-300, doi:10.1016/ S0040-1951(99)00299-1.

Park, J., H. Yuan, and V. Levin (2004), Subduction-zone anisotropy under Corvallis, Oregon: A serpentinite skidmark of trench-parallel terrane migration?, J. Geophys. Res., 109, B10306, doi:10.1029/2003JB002718.

Rondenay, S., M. G. Bostock, and J. Shragge (2001), Multiparameter two-dimensional inversion of scattered teleseismic body waves: 3. Application to the Cascadia 1993 data set, J. Geophys. Res., 106, 30,795-30,807, doi:10.1029/2000JB000039.

Sachpazi, M., A. Galvé, M. Laigle, A. Hirn, E. Sokos, A. Serpetsidaki, J.-M. Marthelot, J. M. Pi Alperin, B. Zelt, and B. Taylor (2007), Moho topography under central Greece and its compensation by Pn timeterms for the accurate location of hypocenters: The example of the Gulf of Corinth 1995 Aigion earthquake, Tectonophysics, 440, 53-65, doi:10.1016/j.tecto.2007.01.009.

Sodoudi, S., R. Kind, D. Hatzfeld, K. Priestley, W. Hanka, K. Wylegalla, G. Stavrakakis, A. Vafidis, H.-P. Harjes, and M. Bohnhoff (2006), Lithospheric structure of the Aegean obtained from $\mathrm{P}$ and $\mathrm{S}$ receiver functions, J. Geophys. Res., 111, B12307, doi:10.1029/2005JB003932.

Stammler, K. (1993), Seismichandler-Programmable multichannel data handler for interactive and automatic processing of seismological analyses, Comput. Geosci., 19, 135-140, doi:10.1016/0098-3004(93)90110-Q

Suckale, J., S. Rondenay, M. Sachpazi, M. Charalampakis, A. Hosa, and L. H. Royden (2009), High-resolution seismic imaging of the western Hellenic subduction zone using teleseismic scattered waves, Geophys. J. Int., 178, 775-791, doi:10.1111/j.1365-246X.2009.04170.x.

van der Meijde, M., S. van der Lee, and D. Giardini (2003), Crustal structure beneath broad-band seismic stations in the Mediterranean region, Geophys. J. Int., 152, 729-739, doi:10.1046/j.1365-246X.2003.01871.x.

Wortel, M. J. R., and W. Spakman (2000), Subduction and slab detachment in the Mediterranean-Carpathian region, Science, 290, 1910-1917, doi:10.1126/science.290.5498.1910.

M. Charalampakis and M. Sachpazi, Institute of Geodynamics, National Observatory of Athens, Lofos Nymfon, GR-11810 Athens, Greece. (cmarinos@noa.gr; m.sachp@.noa.gr)

J. Diaz, Instituto Jaume Almera, Consejo Superior de Investigaciones Científicas, C/Sole i Sabaris s/n, E-08028 Barcelona, Spain. (jdiaz@ija. csic.es)

A. Gesret, Centre de Géosciences, Mines ParisTech, 35 rue SaintHonoré, F-77305 Fontainebleau CEDEX, France. (alexandrine.gesret@ mines-paristech.fr)

A. Hirn and M. Laigle, Sismologie, Institut de Physique du Globe de Paris, UMR 7514, CNRS, 4 place Jussieu, F-75238 Paris CEDEX 05, France. (hirn@ipgp.fr; laigle@ipgp.fr) 